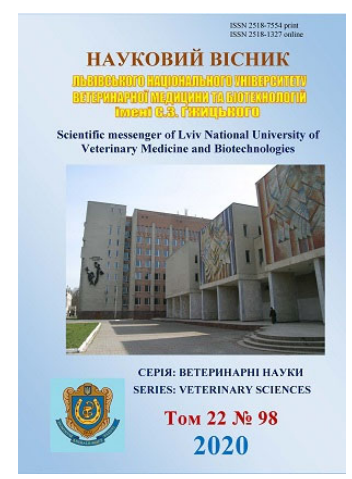

Науковий вісник Яьвівського національного університету ветеринарної медицини та біотехнологій імені С.3. Гжицького. Серія: Ветеринарні науки

\author{
Scientific Messenger of Lviv National University \\ of Veterinary Medicine and Biotechnologies. \\ Series: Veterinary sciences
}

doi: $10.32718 /$ nvlvet9824

https://nvlvet.com.ua/index.php/journal

UDC 619:615.849

\title{
Factors affecting the minimum detected activity of the GAMMAVISION software report protocol
}

T. Vinokurova ${ }^{1}$, Z. Malimon ${ }^{1}$, V. Salata ${ }^{2}$, T. Prokopenko ${ }^{1}$, G. Kochetova ${ }^{1}$, L. Gusak $^{1}$

${ }^{I}$ State Scientific Research Institute of Laboratory Diagnostics and Veterinary Sanitary Expertise, Kyiv, Ukraine

${ }^{2}$ Stepan Gzhytskyi National University of Veterinary Medicine and Biotechnologies Lviv, Ukraine

Article info

Received 30.04.2020

Received in revised form 01.06 .2020

Accepted 02.06.2020

State Scientific Research Institute of Laboratory Diagnostics and

Veterinary Sanitary Expertise,

Donetska Str, 30, Kyiv,

03151, Ukraine.

Tel.: +38-044-242-01-47

E-mail:z_malimon@ukr.net

Stepan Gzhytskyi National University of Veterinary

Medicine and Biotechnologies,

Pekarska Str., 50, Lviv,

79010, Ukraine.

Tel.: +38-067-728-89-33

E-mail: salatavolod@ukr.net
Vinokurova, T., Malimon, Z., Salata, V., Prokopenko, T., Kochetova, G., \& Gusak, L. (2020). Factors affecting the minimum detected activity of the GAMMAVISION software report protocol. Scientific Messenger of Lviv National University of Veterinary Medicine and Biotechnologies. Series: Veterinary sciences, 22(98), 138-143. doi: 10.32718/nvlvet9824

The article presents the results of a gamma-spectrometer study with a low-capacity scintillation (NaI(Tl)) detection unit, with software GammaVision v.8, adopted to solve certification problems, including for measuring activities close to zero. The list of factors influencing the presentation of the minimum detected activity (MDA) in the report protocol is analyzed software GammaVision v.8. To perform the measurements, the company's ORTEC gamma-spectrometer with a low-capacity detection unit a type digiBASE-RH, in which a high-voltage power supply unit, amplifier, digital multi-channel analyzer with USB-connection to a computer with the installed driver are installed, was used. The peak search in the library was performed using a compressed version of the library, which contains two nuclides ${ }^{137} \mathrm{Cs}$ and ${ }^{40} \mathrm{~K}$. Methods of calculating MDA are based on the intensity of accounts. Nuclide activity is calculation for all peaks in the library, the energy of which is in the selected energy ranges for analysis. Measurements and calculations MDA under the given conditions of research for five methods depending on time of measurement and geometry of measurements are carried out. It is shown that the level of MDA can be reduced by choosing the optimal conditions, time of measurement and geometry of measurements. Recommendations are given for the use of capacity for counting sample, which will reduce the amount of substance required for analysis and optimize the time spent on measuring the counting sample. In a prospect it is expedient to undertake a study of dependence of MDA from the physical properties and radionuclide composition of the substance for the counting sample and the dependence from the uncertainty in the equation MDA.

Key words: low capacity detection unit, MDA, calculation methods, measurement conditions, measurement geometry.

\section{Фактори, що впливають на мінімально детектовану активність у протоколі звіту програмного забезпечення GAMMAVISION}

Т. Винокурова ${ }^{1}$, 3. Малімон ${ }^{1}$, В. Салата ${ }^{2}$ Т. Прокопенко ${ }^{1}$, Г. Кочетова ${ }^{1}$, Л. Гусак ${ }^{1}$

${ }^{1}$ Державний науково-дослідний інститут з лабораторної діагностики та ветеринарно-санітарної експертизи, м. Київ, Україна

${ }^{2}$ Львівський наиіональний університет ветеринарної медицини та біотехнологій імені С. 3. Гжищького, м. Львів, Украӥна

У статті наведено результати досліджень гамма-спектрометра з сцинтилячійним (NaI(Tl)) блоком детектування низької здатності, пристосованому для вирішення сертифікаційних задач, у тому числі по вимірюванню активностей близьких до нульових значень. Метою роботи є дослідження залежності МДА від системи аналізу, методів обчислення, часу виміру, геометріі вимірювань з використанням програмного забезпечення GаттаVision v.8. Для виконання вимірювань використано - гамма- 
спектрометр фірми ORTEC, з блоком детектування низької здатності тип digiBASE-RH, в який вмонтовано високовольтний блок живлення, підсилювач, ичирровий багатоканальний аналізатор з USB-підключенням до комп'ютера з встановленим драйвером. Піковий пошук у бібліотеці здійснено з використанням стислої версії бібліотеки, яка містить два нукліди - ${ }^{137}$ Сs та ${ }^{40}$ К. Методи розрахунку МДА трунтуються на інтенсивності рахунків. Активність нуклідів розрахована для всіх піків в бібліотеці, енергія яких знаходиться в обраних діапазонах для аналізу. Проведено виміри і обчислення МДА при заданих умовах дослідження для п'ятьох методів в залежності від часу виміру та геометрії вимірювань. Показано, шуо рівень МДА можна понизити шляхом вибору оптимальних умов, часу виміру, та геометрії вимірювань. Подано рекомендації для застосування ємності для лічильних зразків, щчо зменшить кількість речовини, необхідної для проведення аналізу, та оптимізує час затрачений для виміру лічильного зразка. В перспективі дочільно провести дослідження залежності МДА від фізичних властивостей та радіонуклідного складу речовини для лічильного зразка та залежності від невизначеності в рівнянні МДА.

Ключові слова: блок детектування низької здатності, МДА, методи розрахунку МДА, умови виміру, геометрія вимірювань.

\section{Вступ}

На спектрометрах з сцинтиляційними блоками детектування, в яких визначається відповідність виміряної активності контрольним рівням (NRBU-97/D2000; Kirkpatrick et al., 2013; Malimon et al., 2020), вирішуються сертифікаційні задачі для чотирьох радіонуклідів $\left({ }^{137} \mathrm{Cs},{ }^{40} \mathrm{~K},{ }^{226} \mathrm{Ra},{ }^{232} \mathrm{Th}\right)$. Для деяких випадків ці рівні знаходяться поблизу нульової активності, виникає питання, яка може бути присутня найменша активність, що не виявляється в аналізі - мінімально детектована активність (МДА), які фактори впливають на їі визначення.

Програмне забезпечення GammaVision v.8 дозволяє провести дослідження рівня МДА в залежності від вибору системи аналізу, методу обчислення, часу виміру, геометрії вимірювань, радіонуклідного складу, методу розрахунку фону, невизначеності в рівнянні МДА.

Мета роботи. Дослідження залежності МДА від методів обчислення, часу виміру, геометрії вимірювань 3 використанням програмного забезпечення GammaVision v.8.

\section{Матеріал і методи досліджень}

Система аналізу. Програмне забезпечення GammaVision v.8 - самодостатній програмний продукт, що включає в себе шість систем аналізу. Для аналізу спектра низького дозволу розроблена спеціальна система NAI32. Піковий пошук у бібліотеці буде здійснюватися 3 використанням стислої версії бібліотеки, яка містить два нукліди - ${ }^{137} \mathrm{Cs}$ (використовується для вимірювання вмісту цього нукліду в пробах) та ${ }^{40} \mathrm{~K}$ (разом $3{ }^{137} \mathrm{Cs}$ використовується для калібрування шкали багатоканального аналізатора по енергії).

Мінімальна детектована активність. Програмне забезпечення GammaVision v.8 включає в себе дев'ятнадцять методів розрахунку МДА. В частині методів МДА розраховується на підгрунті фонових піків. Розрахунок МДА для ряду інших методів залежить від площі піка та площі фону. Визначення фону та площі піка змінюється від методу до методу. Розглянемо методи розрахунку площі фону та площі піка.

Розрахунок площі фону. Метод розрахунку площі фону - автоматичний, кількість точок від проекції центроїди до відповідного кінця площі фону (L чи $\mathrm{H})$ дорівнює $N=5$.

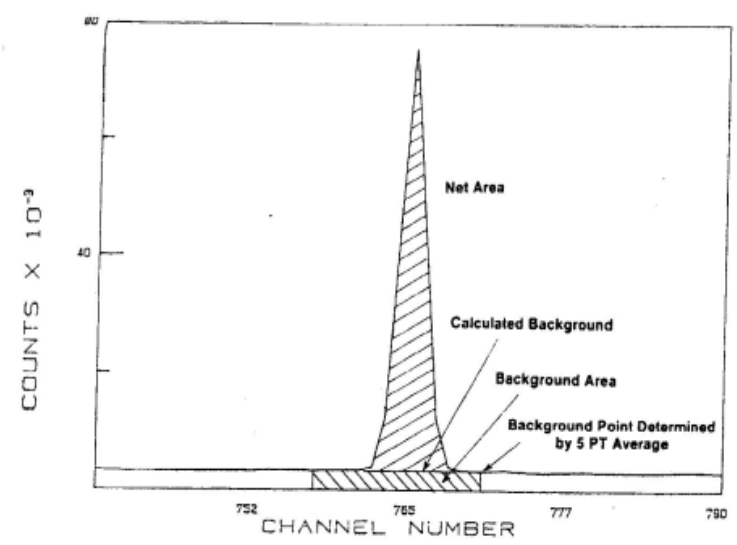

Рис. 1. Розрахунок площі фону

Центр піка (рис. 1) використовується для розрахунку його енергії з використанням існуючого енергетичного калібрування. Якщо показник пікової енергії знаходиться в межах ширини бібліотечного піка, тоді пік буде використовуватися для його аналізу. Якщо площа піка не використовується при розрахунку активності нукліду, так як він не пройшов тест на чутливість, або тест на форму, площа піка додається до площі фону. Якщо фон дорівнює 0, то він встановлюється на 1 для розрахунку МДА. В протоколі звіту фон як і раніше буде дорівнювати 0.

Формула для розрахунку площі фону (Background - площа під піком, визначається інтегральною сумою піка 3 шириною у 2,5 рази FWHM):

$$
B=\left(\frac{B_{1}+B_{2}}{2 \cdot N}\right) \cdot H-L+1
$$

де:

$\mathrm{L}$ - найменший енергетичний канал піка;

$\mathrm{H}$ - найбільший енергетичний канал піка;

$\mathrm{N}=5, \mathrm{FWHM} \mathrm{-} \mathrm{роздільна} \mathrm{здатність} \mathrm{блока} \mathrm{детекту-}$ вання на $1 / 2$ висоті піка, визначається під час енергетичного калібрування (кеВ).

Суми фонових імпульсів на низькому $\mathrm{B}_{1}$ та на високому $\mathrm{B}_{2}$ кінці піка відповідно, розраховується наступним чином:

$$
\begin{aligned}
& B_{1}=\sum_{1}^{N} C_{L B} \\
& B_{2}=\sum_{1}^{N} C_{H B}
\end{aligned}
$$


де:

$\mathrm{C}_{\mathrm{LB}}$ - кількість імпульсів в фоновому каналі на низькому кінці піка;

$\mathrm{C}_{\mathrm{HB}}$ - кількість імпульсів в фоновому каналі на високому кінці піка.

Розрахунок загальної та чистої площі піка. Загальна площа піка це сума вмісту кожного каналу між фоновими каналами (в тому числі два фонових канали, рис.1).

Формула виглядає наступним чином:

$$
A_{g}=\sum_{i=L}^{H} C_{i}
$$

де:

$\mathrm{A}_{\mathrm{g}}$ - загальна площа;

$\mathrm{C}_{\mathrm{i}}$ - параметр даних каналу $\mathrm{i}$;

$\mathrm{L}$ - центральний канал розрахункової ширини фону на низькій енергетичній стороні спектра;

$\mathrm{H}$ - центральний канал розрахункової ширини фону на високій енергетичній стороні спектра.

Даний метод розрахунку площі піка забезпечує точність в ході зменшення піка, він менш чутливий до випадкових коливань даних та до відмінностей між формою піка спектра та формою каліброваного піка. Чиста площа піка (Area Net) це загальна площа піка мінус параметр розрахованого фону. Формула для розрахунку виглядає наступним чином:

$$
\mathrm{A}=\mathrm{Ag}-\mathrm{B}
$$

Для всіх піків бібліотеки у енергетичному діапазоні аналізу, програма намагається вирахувати чисту площу піка та центр піка на цьому каналі. На цьому етапі аналізу, кожен пік вважається синглетним. Це одиночний, ізольований пік, тобто, він знаходиться так далеко від інших піків в спектрі, що спектр являє собою фон по обидві сторони від піка (не перекриває інший пік).

Пікова активність нукліду. Активність нукліду розраховується для всіх піків в бібліотеці, енергія яких знаходиться в обраних діапазонах енергій для аналізу. В даному випадку у бібліотеці для кожного з нуклідів перелічений тільки один пік, тому використовується наступне:

- якщо пік не щільно перекриває інший бібліотечний пік, то він повинен бути заданий в діапазоні аналізу;

- якщо для піка встановлено відмітка ознаки "Не в просторі піка”, то нуклід автоматично відхиляється при використанні всіх механізмів аналізу;

- якщо пік щільно перекриває інший бібліотечний пік, таким чином, що потрібно застосовувати роздільність піка, то невизначеність площі, яка залишається після розділення піка має бути менша ніж відрізання піка.

Питома пікова активність нуклідів (Бк/кг) встановлюється за наступним рівнянням:

де:

$$
\mathrm{A}_{\mathrm{E}}=\xi \cdot \mathrm{N}_{\mathrm{E}}
$$

$$
\xi=\frac{T D C \cdot G e o F a c \cdot A t t}{L T \cdot \varepsilon \cdot B r \cdot m}
$$

$\mathrm{A}_{\mathrm{E}}$ - питома пікова активність нукліду за енергією $E$,(Бк/кг);

$\mathrm{N}_{\mathrm{E}}$ - чиста площа піка для пікової енергії $E$, (Counts - кількість відкликів);

TDC - коефіцієнт корегування розпаду;

LT - час набору спектра, (c);

$\varepsilon-$ ефективність реєстрації детектору в залежності від енергії $E$;

$\mathrm{Br}$ - кількість виходу $\gamma$-квантів на 100 розпадів нукліда піка;

GeoFac - коефіцієнт корекції геометрії;

Att - коефіцієнт поправки на затухання;

$\mathrm{m}$ - маса зразку (кг).

Обчислення МДА. Методи розрахунку МДА базуються на інтенсивності рахунків $C R_{M B A}$ (cts/sec). Перерахунок інтенсивності рахунку $C R_{\mathrm{mda}}$ (кількість рахунків за секунду) на активність МДА (Бк) відбувається за формулою:

$$
\text { МДА (Бк })=\xi \mathrm{CR}_{\mathrm{mda}} \cdot \mathrm{LT}
$$

Методи МДА у програмному забезпеченні GammaVision 8.0. Програмне забезпечення GammaVision v.8 дозволяє вибір методу розрахунку для представлення МДА в протоколах звіту.

Умови виконання дослідження, для яких було проведено обчислення МДА для протоколу звіту:

1. Умови виконання вимірювань: гаммаспектрометр фірми ORTEC, з блоком детектування низької здатності тип digiBASE-RH, в який вмонтовано високовольтний блок живлення, підсилювач, цифровий багатоканальний аналізатор 3 USBпідключенням до комп'ютера 3 встановленим драйвером;

- програмне забезпечення комп'ютера OC Windows 7, Microsoft Word 2010;

- програмне забезпечення GammaVision, v.8;

- система захисту свинцева, комбінована; ${ }^{40} \mathrm{~K}$.

- калібрувальне джерело 3 радіонуклідами ${ }^{137} \mathrm{Cs}$,

2. Умови виконання обчислення:

- система аналізу $\mathrm{NaI} 32$;

- піковий пошук у бібліотеці здійснюється з використанням стислої версії, яка містить два нукліди ${ }^{137} \mathrm{Cs}$ та ${ }^{40} \mathrm{~K}$;

- діапазон досліджень 0 - 1024 канали;

- метод розрахунку фону - автоматичний;

- роздільна здатність детектора по енергії 661,66 кеВ (радіонуклід ${ }^{137} \mathrm{Cs}$ ) на пів-висоті FWHM дорівнює $7,5 \%$;

- максимальне значення на яке центроїд піка може відхилитися від найближчого бібліотечного піка енергії і все ще бути пов'язаним з цим піком дорівнює 0,5 FWHM;

- ефективність реєстрації (за результатами калібрування перед початком вимірювань) по енергії 661,66 кеВ дорівнює $3,9 \cdot 10^{-2}$ (у відносних одиницях);

- чутливість пошуку піка (PEAK SEARCH SENSITIVITY) встановлено на значенні 3;

- відсікання піка (Peak Cutoff) встановлено на значенні $100 \%$;

- геометрія вимірювань - Марінеллі 1 л. 
Для дослідження було вибрано п’ять методів обчислення МДА. Перед початком кожного вимірювання проводилося калібрування шкали багатоканального АЦП по енергії.

\section{Таблиця 1}

Обчислені значення МДА (одиниця виміру Бк/кг), в залежності від часу набору спектра

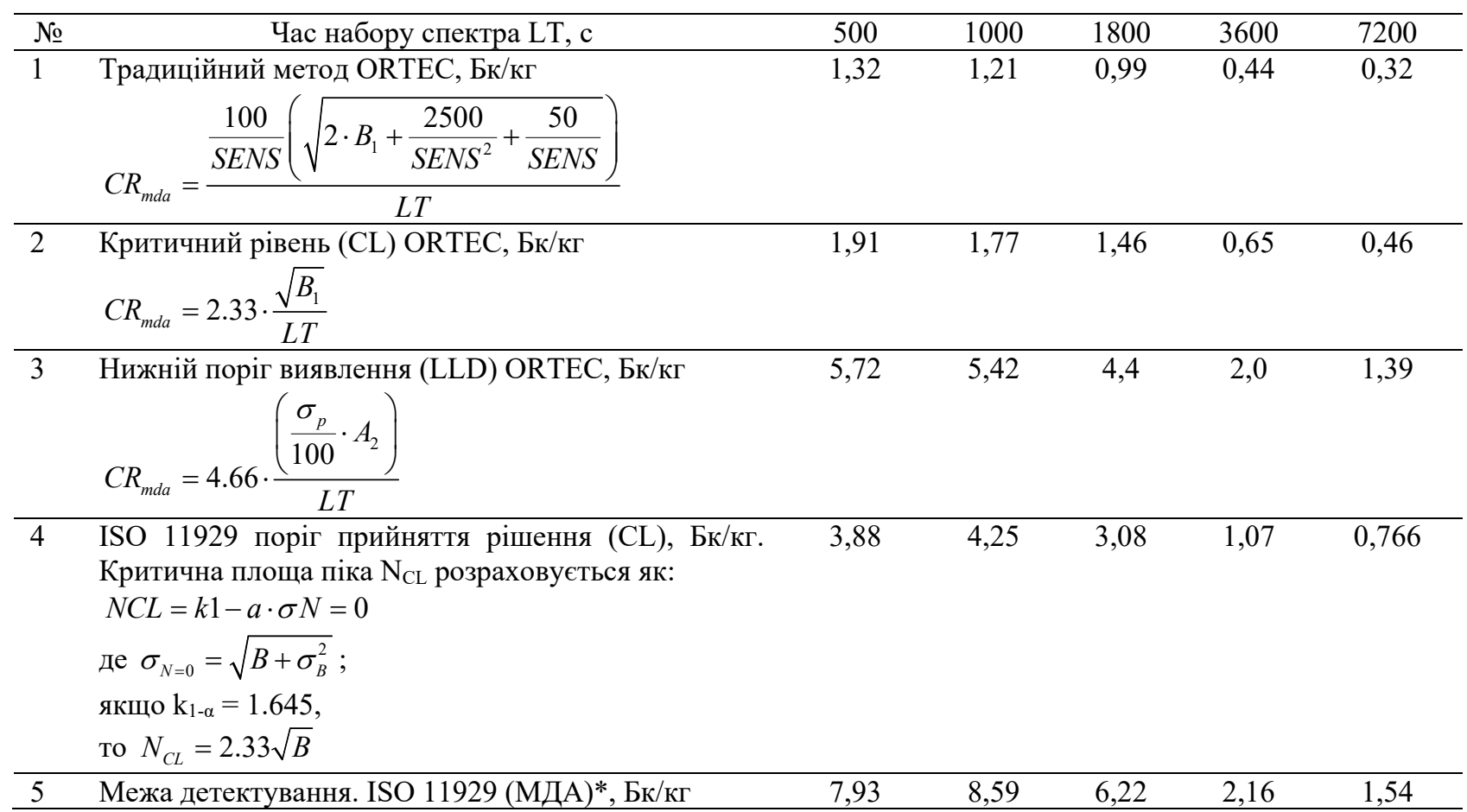

Значення МДА в залежності від методу обчислення.

$$
L D_{\text {Net }}=\frac{\left(2 \cdot S D_{\text {Net }}+k_{1-\beta}^{2}+\sqrt{\left(2 \cdot S D_{N e t}+k_{1-\beta}^{2}\right)^{2}-4 \cdot\left(1-k_{1-\beta}^{2} \cdot \sigma \% \hat{\tilde{R}}\right) \cdot\left(1-\frac{k_{1}^{2}-\beta}{k_{1}^{2}-\alpha}\right) \cdot S D_{\text {Net }}^{2}}\right)}{2 \cdot\left(1-k_{1-\beta}^{2} \cdot \sigma \% \frac{\hat{R}}{R}\right)}
$$

Пояснення до таблиці 1.

Метод 1. Традиційний метод ORTEC. Якщо відсікання піка (Peak Cutoff) встановлено на значенні $100 \%$, то

$$
C R_{\text {mda }}=\frac{1.41}{L T} \sqrt{B}
$$

Метод 2. Критичний рівень (CL) ORTEC використовують для якісного аналізу, для перевірки перевищення корисним сигналом заданого рівня флуктуації фону. CL - найменша концентрація радіоактивного матеріалу в зразку, який буде давати чистий відклик, що буде виявлений з ймовірністю 0,95 (GammaVision, 2017).

Метод 3. Нижня межа детектування (LLD) ORTEC - найменша активність одного радіонукліду в зразку, що створює такий чистий відклик, котрий дозволяє визначити активність даного радіонукліду з довірчою імовірністю 0.95 (GammaVision, 2017).

Метод 4. ISO 11929-3:2019. Поріг прийняття рішення (decision threshold) (ISO/DIS 11929-3:2019).

$\mathrm{A}_{\mathrm{CL}}=\xi \cdot \mathrm{N}_{\mathrm{CL}}$; критична площа піка $\mathrm{N}_{\mathrm{CL}}$ розраховується як:

$$
\begin{gathered}
\mathrm{N}_{\mathrm{CL}}=\mathrm{k}_{1-\alpha} \cdot \sigma_{\mathrm{N}=0, \text { де: }} \\
\sigma_{N=0}=\sqrt{B+\sigma_{B}^{2}}
\end{gathered}
$$

якщо $\mathrm{k}_{1-\alpha}=1.645$, то

$$
N_{C L}=2.33 \sqrt{B}
$$

Поріг прийняття рішення - фіксоване значення виміру, при перевищенні котрого фізичний ефект присутності є в наявності (ISO/DIS 11929-3:2019).

Метод 5. ISO 11929-3:2019. Detection Limit. Межа детектування використовується для того, щоб у випадку її перевищення чистою швидкістю рахунку, гарантувати виявлення радіонукліда в зразку з довірчою імовірністю не нижче 0,95 (GammaVision, 2017; ISO/DIS 11929-3:2019). Де LD $\mathrm{Net}_{\mathrm{N}}$ - поріг детектування (МДА GammaVision), SD $\mathrm{Set}_{\mathrm{N}}$ - поріг прийняття рішення (критичний рівень GammaVision) та $\sigma \% \mathrm{R}-$ невизначеність коефіцієнту перерахунку чистих підрахунків на одиниці активності.

В таблиці 2 наведені результати обчислення значень критичного рівня (CL) ORTEC і нижньої межи детектування (LLD) МДА ORTEC в залежності від часу виміру. 
Таблиця 2

Обчислені значення МДА в залежності від часу виміру (методи фірми ORTEC)

\begin{tabular}{lrrrrr}
\hline Час виміру LT, с. & 500 & 1000 & 1800 & 3600 & 7200 \\
\hline Критичний рівень (CL), Бк/кг & 1,90 & 1,77 & 1,46 & 0,65 & 0,46 \\
Нижня межа детектування (LLD), Бк/кг & 5,72 & 5,42 & 4,40 & 2,00 & 1,39 \\
Відношення LLD/CL, Бк/кг & 3.01 & 2,96 & 3,01 & 3,10 \\
\hline
\end{tabular}

Таблиця 3

Обчислені значення МДА, в залежності від часу виміру (методи ISO 11929)

\begin{tabular}{llllll}
\hline \multicolumn{1}{c}{ Час виміру LT, с. } & 500 & 1000 & 1800 & 3600 & 7200 \\
\hline Поріг прийняття рішення, Бк/кг & 3,88 & 4,25 & 3,08 & 1,07 & 0,77 \\
Межа детектування & 7,93 & 8,59 & 6,22 & 2,16 & 1,54 \\
Відношення межи детектування до порога прийняття рішення, & 2,04 & 2,02 & 2,02 & 2,02 & 2,01 \\
Бк/кг & & & \\
\hline
\end{tabular}

3 рисунку 2 видно характер залежності МДА від часу виміру для двох методів представлення МДА (фірма) ORTEC у протоколі звіту (1 - Критичний рівень (CL); 2 - Нижня межа детектування (LLD)).

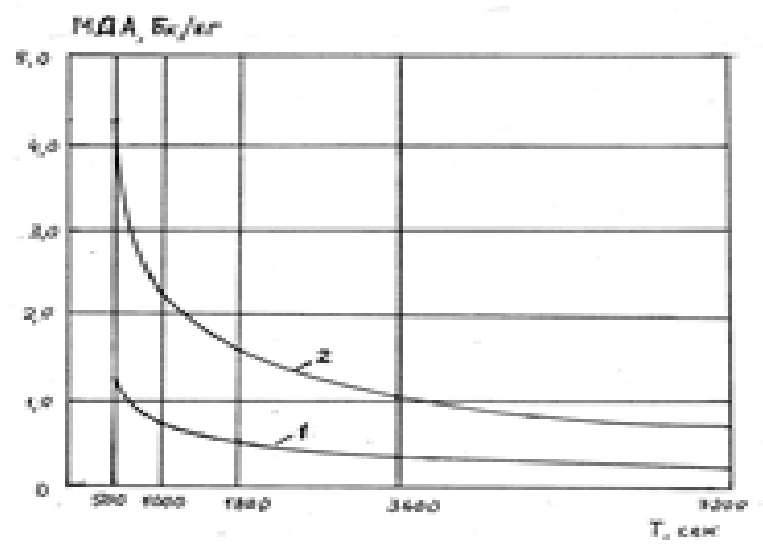

Значення МДА в залежності від геометрії виміру. Кількісне визначення вмісту радіонуклідів у лічильному зразку пов'язано з визначенням ефективності

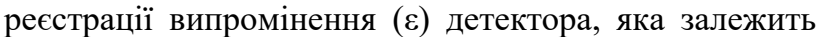
від геометрії вимірювань, енергії частинок, що опромінюють детектор, затухання випромінення як в лічильному зразку, так і в самому детекторі, від взаємного розміщення ємності з лічильним зразком і детектора. Точний розрахунок усіх факторів, що впливають на визначення ефективності дуже важкий процес (GammaVision, 2017). Для визначення ефективності реєстрації в залежності від геометрії вимірювання було використано достатньо відомий і простий метод - пряме експериментальне калібрування детектора по ефективності реєстрації для трьох варіантів: посудина Марінеллі 1л, посудина Марінеллі 0,5л, чашка Петрі Ø 90x10 мм.

Рис. 2. Залежність МДА від часу виміру

Таблиця 4

Обчислені значення МДА в залежності від часу виміру

\begin{tabular}{lcccc}
\hline \multicolumn{1}{c}{ Час виміру LT, сек } & 1000 & 1800 & 3600 & 7200 \\
\hline Марінеллі 1 л, Бк/кг & 14,7 & 7,9 & 2,7 & 1,8 \\
Марінеллі 0,5 л, Бк/кг & 22,2 & 14,1 & 4,5 & 3,2 \\
Чашка Петрі, Бк/кг & 83,8 & 48,0 & 19,2 & 13,7 \\
\hline
\end{tabular}

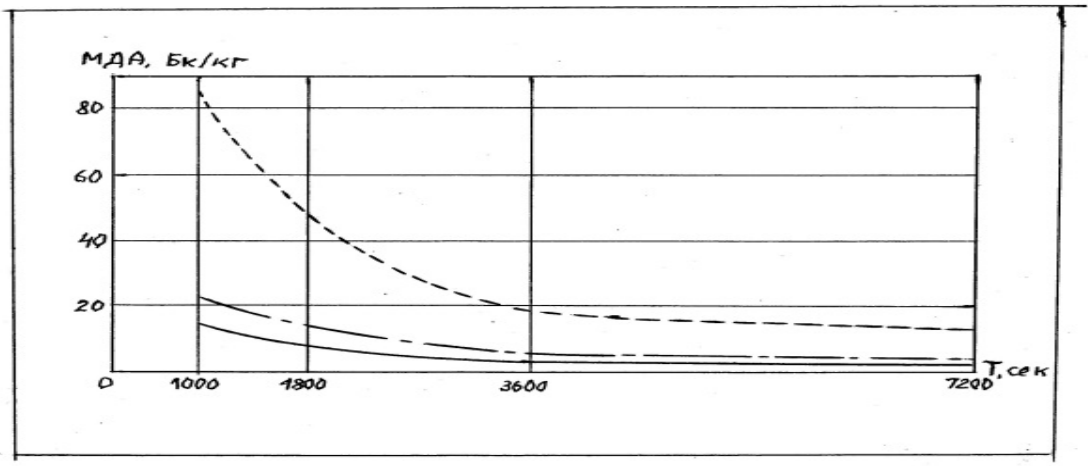

Рис. 3. Значення МДА в залежності від часу виміру для трьох геометрій: Марінеллі - 1 л, Марінеллі - 0,5 л, чашка Петрі. 


\section{Результати та їх обговорення}

Згідно даних в таблицях 2 і 3 обчислення, проведені за різними методам відрізняються:

- відношення нижньої межі детектування (LLD) до критичного рівня (CL) (фірма ORTEC) дорівнює $3,0 \pm 3 \%$;

- відношення межі детектування до порога прийняття рішення (ISO 11929-3: 2019) дорівнює 2,0 $05 \%$.

Нижня межа детектування (МДА) приблизно у три рази перевищує критичний рівень. В залежності від значень контрольних рівнів в інтервалі 1-4 Бк/кг, час виміру лічильного зразка для підтвердження відповідності (Nakaz MOZ Ukrainy) від 500 с до 7200 c.

Результати обчислення значення МДА в залежності від геометрії виміру, наведені в таблиці 4 і рисунку 3. 3 яких видно, що для перевірки відповідності виміряної активності радіонуклідів, присутніх у лічильному зразку, контрольним рівням порядку 2 10 Бк/кг оптимальні ємності для лічильного зразка Марінеллі 1 л та Марінеллі 0,5 л. Обчислення малих активностей потребує достатньо великого часу виміру, але він обмежений вимогами стабільності спектрометра.

Для перевірки відповідності виміряної активності радіонуклідів, присутніх у лічильному зразку, контрольним рівням більше 20 Бк/кг - допустимо застосовувати ємності для лічильного зразка типу “чашка Петрі” 0,07 л, що значно скоротить кількість речовини необхідної для аналізу.

\section{Висновки}

1. Проведено оцінку факторів, що впливають на представлення МДА в протоколі звіту п/о GammaVision 8.0.

2. Проведені виміри і обчислення МДА за заданих умов дослідження для п'ятьох методів (три методи ORTEC і два методи - ISO 11929-3:2019).

3. Показано, що можна наблизити МДА до мінімальних значень при оптимальному виборі умов виконання дослідження, часу та геометрії вимірювань.
4. Подано рекомендації для застосування ємності для лічильних зразків, що зменшить кількість речовини, необхідної для проведення аналізу, та оптимізує час, затрачений на вимір зразка.

Перспективи подальших досліджень. Доцільно провести дослідження МДА з урахуванням фізичних властивостей та радіонуклідного складу речовини для лічильного зразка, та залежності від невизначеності в рівнянні МДА.

\section{References}

GammaVision (2017). Gamma-Ray Spectrum Analysis and MCA Emulator for Microsoft Windows 7, 8.1, and 10 Professional. A66-BW Software User's Manual. 480 p. URL: https://www.ortec-online.com//media/ametekortec/manuals/a66-mnl.pdf.

ISO/DIS 11929-3:2019. Determination of characteristic limits (decision threshold, detection limit, and limits of the confidence interval) for measurements of ionizing radiation - Fundamentals. URL: https://www.iso.org/obp/ui/\#iso:std:69581:en.

Kirkpatrick, J. M., Venkataraman, R., \& Young, B. M. (2013). Minimum detectable activity, systematic uncertainties, and the ISO 11929 standart. J. Radioanal Nucl Chem, 296, 1005-1010. doi: 10.1007/s10967012-2083-5.

Malimon, Z. V., Salata, V. Z., Kochetova, G. S., Prokopenko, T. O., \& Gusak, L. M. (2020). Analysis of radiouclide contamination of forestry products on the territory of Ukraine 2013-2019. Scientific Messenger of Lviv National University of Veterinary Medicine and Biotechnologies. Series: Veterinary sciences, 22(97), 47-51. doi: 10.32718/nvlvet9709.

Nakaz MOZ Ukrainy № 256 vid 03.05.2006 r. Dopustymi rivni vmistu radionuklidiv $137 \mathrm{Cs}$ i $90 \mathrm{Sr}$ u produktakh kharchuvannia ta pytnii vodi (in Ukrainian).

Normy radiatsiinoi bezpeky Ukrainy (NRBU-97/D-2000). URL: http://consultant.parus.ua/?doc $=052$ UL932A5 (in Ukrainian). 